\title{
Improved Carrier Function and Optimal Structure for Stepped Wave Inverters
}

\author{
A.Mohandoss ${ }^{1}$, K.Sivaramachandran ${ }^{2}$, R.Radhakrishnan ${ }^{3}$ \\ P.G. Scholar, Electrical Drives \& Embedded control, RVS College of Engineering \& Technology, Coimbatore, India ${ }^{1}$ \\ P.G. Scholar, Embedded Systems Technologies, RVS College of Engineering \& Technology, Coimbatore, India ${ }^{2}$ \\ P.G. Scholar, Power Electronics \& Drives, Anna University Regional Centre, Coimbatore, India ${ }^{3}$
}

\begin{abstract}
Multilevel inverters include an array of power semiconductor devices and capacitor voltage sources, the output of which cause voltages with stepped waveforms to have compact distortion. The term multilevel starts with the three-level inverter introduced by Nabae et al. The most attractive features of multilevel inverters include output voltages with extremely low distortion, lower $\mathrm{dv} / \mathrm{dt}$, input current with very low distortion, generate smaller commonmode $(\mathrm{CM})$ voltage (thus reducing the stress in the motor bearings), lower switching frequency, etc. The main advantage of this topology is that it does not need additional diodes or capacitors for implementation. The operation of the flying capacitor multilevel inverter topology is based on the connection of capacitors, without using extra diodes. The most important advantage of this topology is that the number of switching combinations through which a same output voltage level can be achieved and hence allows a better distribution of the energy demanded from the capacitors. A new topology has to be proposed that provide higher number of level with optimum number of devices and dc voltage sources. A generalized structure has to be derived that brings easier implementation for desired output voltages for medium voltage applications. Also a new modulation technique is proposed which enhances the fundamental voltage and reduces the Total Harmonic Distortion (THD).
\end{abstract}

Keywords: Modified cascaded multi-level dc link inverter, Multi career PWM, $60^{\circ}$ PWM technique, THD

\section{INTRODUCTION}

In recent years industrial applications have begun to switching frequency based PWM. It would be eminent that require higher power applications and medium voltage lower switching frequency usually means lower switching motor drives require medium voltage and megawatt power loss and higher efficiency. Plentiful multilevel inverter level as well. As a effect, a multilevel power converter topologies have engaged contemporary research on novel structure has been introduced in 1975 as an alternative in inverter topologies and unique modulation structures. high power and medium voltage applications through a Besides, three different foremost multilevel inverter series of power semiconductor switches with several low structures have been reported in the literature: cascaded Hvoltage dc sources to perform the power conversion by bridges inverter with separate dc sources, diode clamped synthesizing a staircase voltage waveform. The (neutral-clamped), and flying capacitors (capacitor commutation of the power switches aggregate these clamped). Moreover, newer modulation techniques have multiple dc sources in order to achieve high voltage at the been developed for multilevel inverters such as sinusoidal output and the rated voltage of the power semiconductor pulse width modulation (SPWM), selective harmonic switches depends only upon the rating of the dc voltage elimination (SHE-PWM), space vector modulation sources to which they are connected. Subsequently, (SVM), which is simple an extension of two level several multilevel converter topologies have been modulation. developed. The attractive features of a multilevel inverter are,

(i) Staircase waveform quality: Multilevel inverters not only can generate the output voltages with very low distortion, but also can reduce the $\mathrm{dv} / \mathrm{dt}$ stresses; therefore electromagnetic compatibility (EMC) problems can be reduced.

(ii) Common-mode (CM) voltage: Multilevel inverters produce smaller $\mathrm{CM}$ voltage; therefore, the stress in the motor bearings allied to a multilevel drive can be reduced.

(iii) Input current: Multilevel inverters can draw input current with low distortion.

(iv) Switching frequency: Multilevel inverters can operate at both fundamental switching frequency and high 


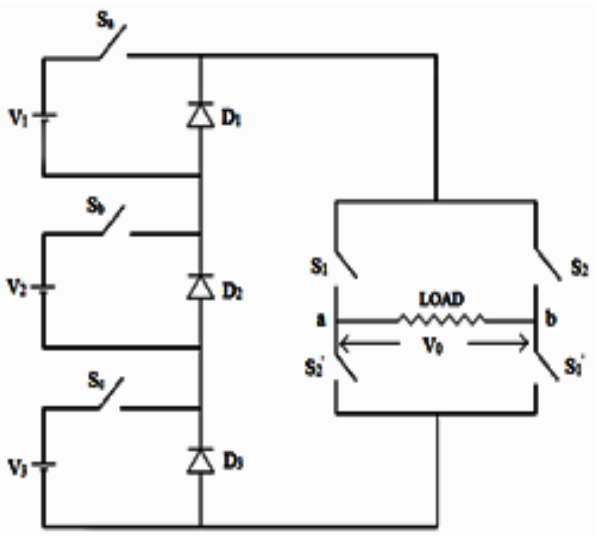

Fig.1. Generalized CMLDCLI

The proposed topology composed of several sub multilevel cells constituted by isolated voltage sources connected in series with power switch and a power diode in parallel as shown in Fig. 2.1. Each sub-multilevel cell is capable of producing three levels using only a dc source.

\section{A. Modes of Operation}

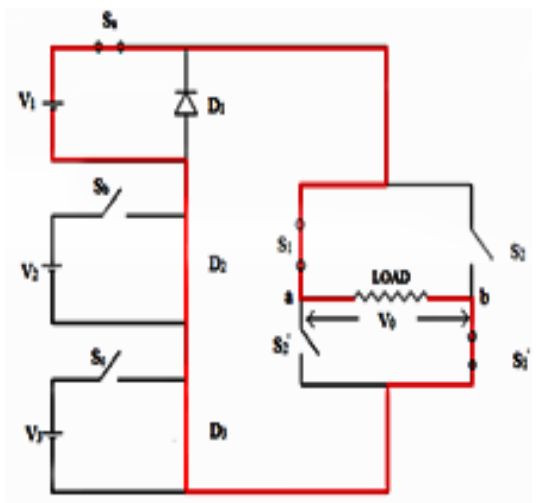

Fig.2. Mode 1 circuit operation

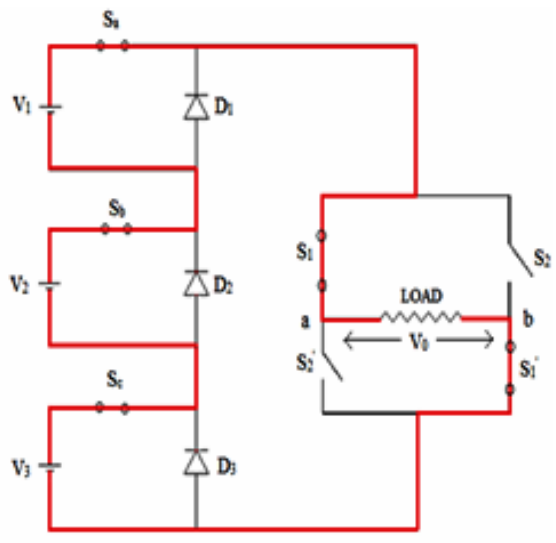

Fig.4. Mode 3 Circuit Operation

Linking the voltage sources $\left(V_{1}+V_{2}+V_{3}\right)$ to the load, the switches $S_{a}, S_{b}, S_{c}, S_{1}, S_{1}^{\prime}$ are turned on, the current flows from sources $\left(V_{1}+V_{2}+V_{3}\right), S_{a}, S_{1}$, load, $S_{1}^{\prime}$ and back to the source as depicted in Fig. 4.

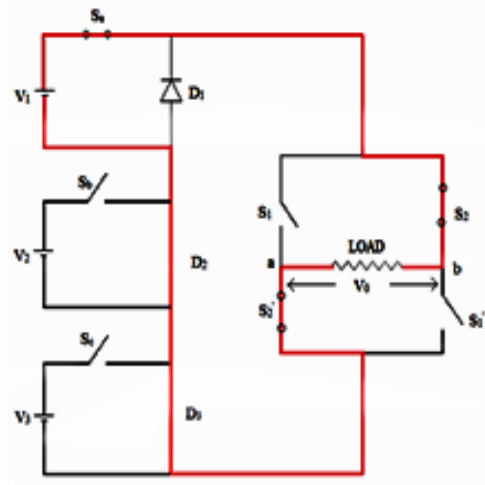

Fig.5. Mode 4 Circuit Operation

Linking the voltage source to produce $-\mathrm{V}_{1}$ across the load, the switches $S_{a}, S_{2}, S_{2}^{\prime}$ are turned on, the current flows from source $\mathrm{V}_{1}, \mathrm{~S}_{\mathrm{a}}, \mathrm{S}_{2}$, load, $\mathrm{S}_{2}^{\prime}$ and back to the source through the doides $\mathrm{D}_{2}$ and $\mathrm{D}_{3}$ as shown in the fig. 2.6. Linking the voltage sources to produce $-\left(\mathrm{V}_{1}+\mathrm{V}_{2}\right)$ across the load, the switches $S_{a}, S_{b}, S_{2}, S_{2}^{\prime}$ are turned on, the current flows from sources $\left(\mathrm{V}_{1}+\mathrm{V}_{2}\right), \mathrm{S}_{\mathrm{a}}, \mathrm{S}_{2}$, load, $\mathrm{S}_{2}^{\prime}$ and back to the source through the doide D3 and D2 as shown in the fig. 2.7. across the load, the switches $\mathrm{S}_{\mathrm{a}}, \mathrm{S}_{\mathrm{b}}, \mathrm{S}_{2}, \mathrm{~S}_{2}^{\prime}$ are turned on, the current flows from sources $\left(V_{1}+V_{2}\right), S_{a}$, $\mathrm{S}_{2}$, load, $\mathrm{S}_{2}^{\prime}$ and back to the source through the doide D3 and D2 as shown in the fig. 5. The proposed topology synthesizes rectified multilevel dc-link voltage through a series of sub multilevel cells and alternated to produce unfolded multilevel waveform across an $\mathrm{H}$-bridge inverter. Few sub cells are required to produce more number of levels by holding unequal voltage ratios in this structure.

Table 1. Switching strategy

\begin{tabular}{|c|c|c|c|c|c|c|c|}
\hline Level & $\mathbf{S}_{\mathbf{a}}$ & $\mathbf{S}_{\mathbf{b}}$ & $\mathbf{S}_{\mathbf{c}}$ & $\mathbf{S}_{\mathbf{1}}$ & $\mathbf{S}_{\mathbf{1}}{ }^{\prime}$ & $\mathbf{S}_{\mathbf{2}}$ & $\mathbf{S}_{\mathbf{2}}{ }^{\prime}$ \\
\hline$+\mathbf{V}_{\mathbf{d c}}$ & 1 & 1 & 1 & 1 & 1 & 0 & 0 \\
\hline$+\mathbf{2} \mathbf{V}_{\mathbf{d c}} / \mathbf{3}$ & 1 & 1 & 0 & 1 & 1 & 0 & 0 \\
\hline$+\mathbf{V}_{\mathbf{d c}} / \mathbf{3}$ & 1 & 0 & 0 & 1 & 1 & 0 & 0 \\
\hline $\mathbf{0}$ & 0 & 0 & 0 & 0 & 0 & 0 & 0 \\
\hline$-\mathbf{V}_{\mathbf{d c}} / \mathbf{3}$ & 1 & 0 & 0 & 0 & 0 & 1 & 1 \\
\hline$-\mathbf{2} \mathbf{V}_{\mathbf{d c}} / \mathbf{3}$ & 1 & 1 & 0 & 0 & 0 & 1 & 1 \\
\hline $\mathbf{- V d c}$ & 1 & 1 & 1 & 0 & 0 & 1 & 1 \\
\hline
\end{tabular}

Linking the voltage sources $\left(\mathrm{V}_{1}+\mathrm{V}_{2}\right)$ to the load, the switches $S_{a}, S_{b}, S_{1}, S_{1}^{\prime}$ are turned on, the current flows from source $\left(V_{1}+V_{2}\right), S_{a}, S_{1}$, load, $S_{1}^{\prime}$ and back to the source through the doide $\mathrm{D}_{3}$ and $\mathrm{D}_{2}$ as in the fig. 3 


\section{III.IMPROVED PWM TECHNIQUE}

PWM techniques are used for controlling the output voltage and frequency of the inverter. Conventional PWM techniques like sinusoidal PWM or MCPWM suffers with higher Total Harmonic Distortion (THD) and lower fundamental voltage. This chapter proposes a novel carrier based technique that offers enhanced fundamental voltage with reduced THD.

\section{A. Multi career PWM}

In this PWM technique, the triangular carrier signal is compared with the reference sinusoidal signal to produce the PWM signal. The main disadvantages of this PWM technique are the higher THD, lower fundamental voltage and more switching losses. The carrier signal and the PWM signal is shown in the Fig 6.

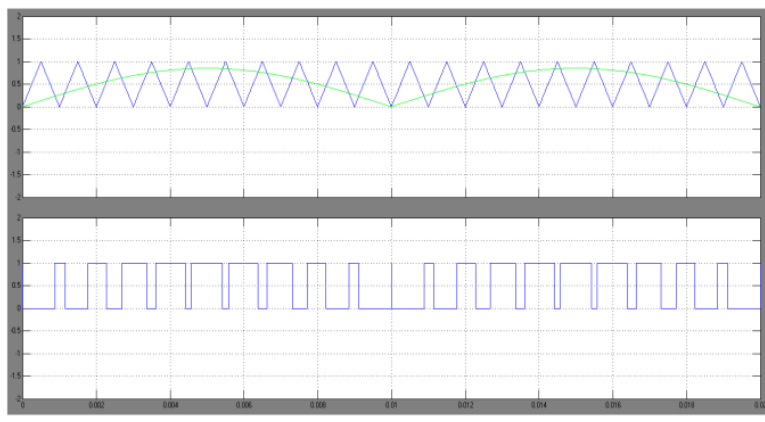

Fig.6. Carrier and PWM Signal

The PWM techniques include Phase Disposition (PD) PWM, Phase Opposition, Disposition (POD) PWM, Alternative Phase Opposite Disposition (APOD) PWM, Carrier Overlapping (CO) PWM, Phase Shift (PS) PWM and also Variable Frequency Carrier Band (VFCB) PWM.

\section{B. $60^{\circ} \mathrm{PWM}$ Technique}

In this technique, the switches are held on continuously for the period from $60^{\circ}$ to $120^{\circ}$. The pulse width from $60^{\circ}$ to $120^{\circ}$ doesn't have significant variation with change in modulation index. This technique results in enhanced fundamental voltage, reduced THD and reduced switching losses. With this technique, the triplen harmonics are eliminated in phase PWM inverters.

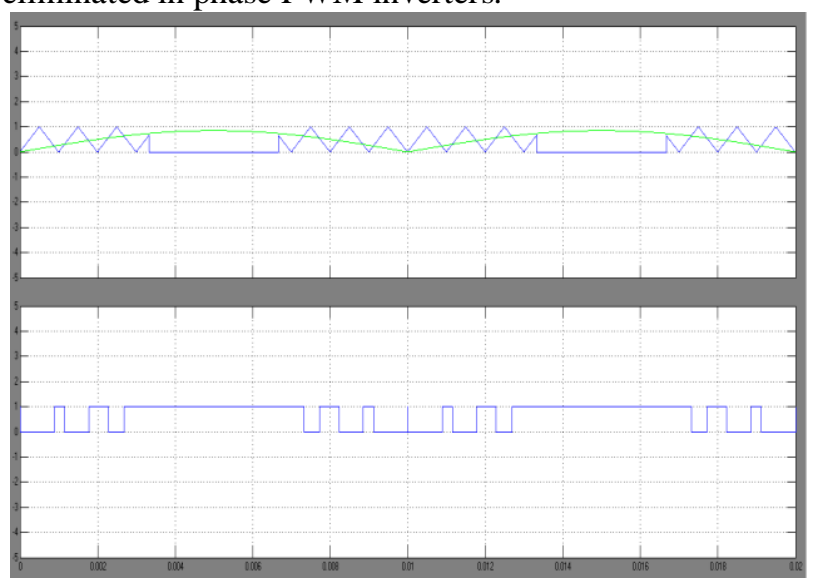

Fig.7. Carrier and PWM Signal
Table.2. Comparison between proposed PWM and MCPWM in terms of Fundamental output voltage

\begin{tabular}{|c|c|c|}
\hline $\mathrm{M}_{\mathrm{a}}$ & $60^{\circ} \mathrm{PWM}(\mathrm{V})$ & MCPWM $(\mathrm{V})$ \\
\hline 1 & 305.4 & 298.8 \\
\hline 0.98 & 303 & 292.6 \\
\hline 0.96 & 300.5 & 286.4 \\
\hline 0.94 & 298.3 & 280.3 \\
\hline 0.92 & 296.4 & 274.7 \\
\hline 0.9 & 294.7 & 269.2 \\
\hline 0.88 & 292.9 & 263.7 \\
\hline 0.86 & 290.4 & 257.4 \\
\hline 0.84 & 287.7 & 251 \\
\hline 0.82 & 285.2 & 244.7 \\
\hline
\end{tabular}

This chapter provides an insight analysis towards the conventional PWM methods in terms of switching, fundamental output voltage and distortion. Based on this, a new PWM technique called $60^{\circ} \mathrm{PWM}$ that reduces the switching loss at the verge of the reference sine wave in the carrier. This proposed scheme projects results in enhanced fundamental output voltage, reduced THD and reduced switching loss.

Table. 3. Comparison between proposed PWM and MCPWM in terms of THD

\begin{tabular}{|c|c|c|}
\hline $\mathrm{M}_{\mathrm{a}}$ & $60^{\circ} \mathrm{PWM}(\%)$ & MCPWM (\%) \\
\hline 1 & 16.07 & 17.93 \\
\hline 0.98 & 16.3 & 19.09 \\
\hline 0.96 & 16.47 & 20.01 \\
\hline 0.94 & 16.63 & 20.78 \\
\hline 0.92 & 16.92 & 21.53 \\
\hline 0.9 & 17.19 & 22.12 \\
\hline 0.88 & 17.42 & 22.52 \\
\hline 0.86 & 18.16 & 23.14 \\
\hline 0.84 & 19.03 & 23.65 \\
\hline 0.82 & 19.82 & 23.94 \\
\hline
\end{tabular}

\section{IV.RESULTS AND DISCUSSION}

Having a detailed introduction and complete review from preceding chapters, one need study through simulation for understanding. In this chapter, the MCPWM and the proposed topology are simulated in MATLAB. A seven level output is considered for study. Specifications of simulations results presented are $\mathrm{V}_{1}: \mathrm{V}_{3=1} 1: 1: 1$, Resistive load $=100 \Omega$

\section{A. Multi career PWM}

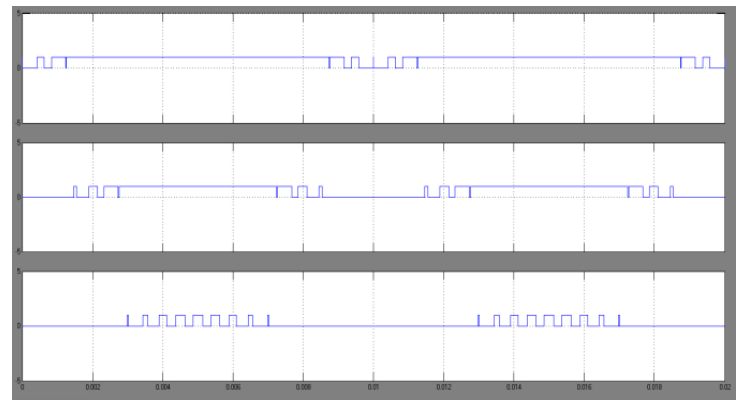

Fig.8. Pulse Pattern 


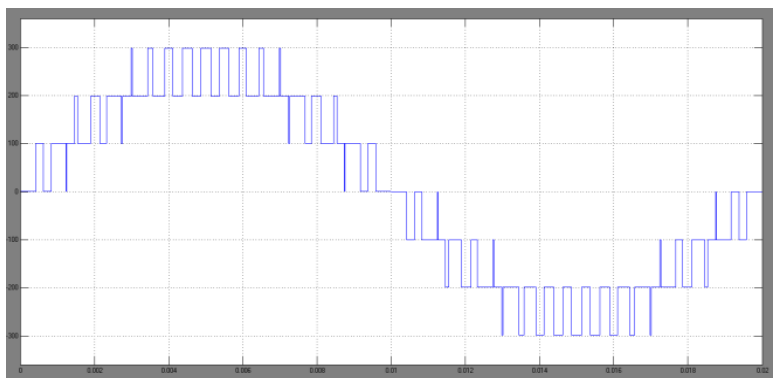

Fig.9. Output Voltage

The pulse pattern of multi career PWM signal is shown in fig. 8 and fig. 9 shows the output voltage signal. The fig. 10 illustrates the voltage spectrum of multi career signal

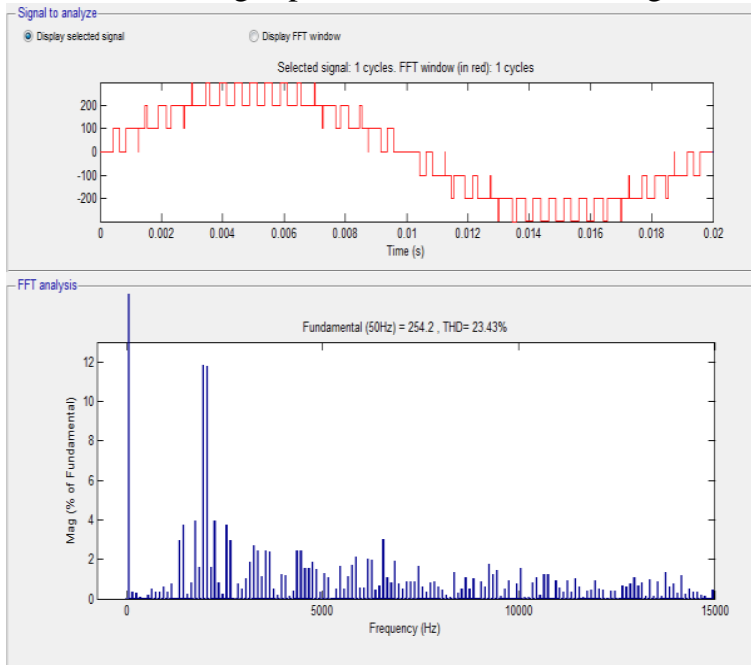

Fig.10. Voltage Spectrum

B. $60^{\circ} P W M$ Technique

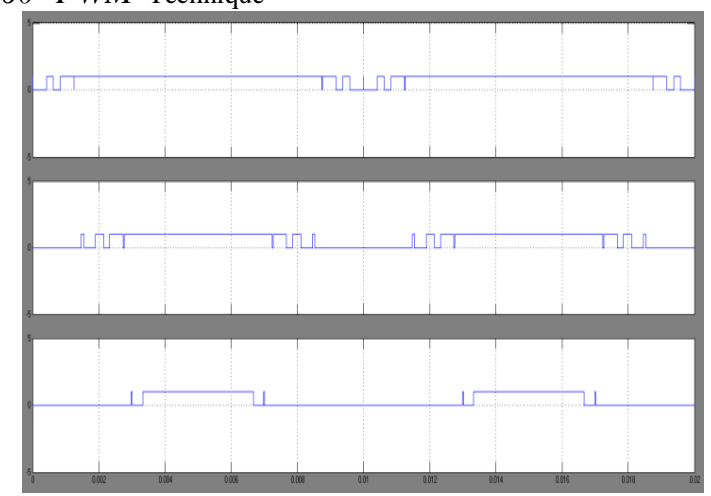

Fig.11. Pulse Pattern

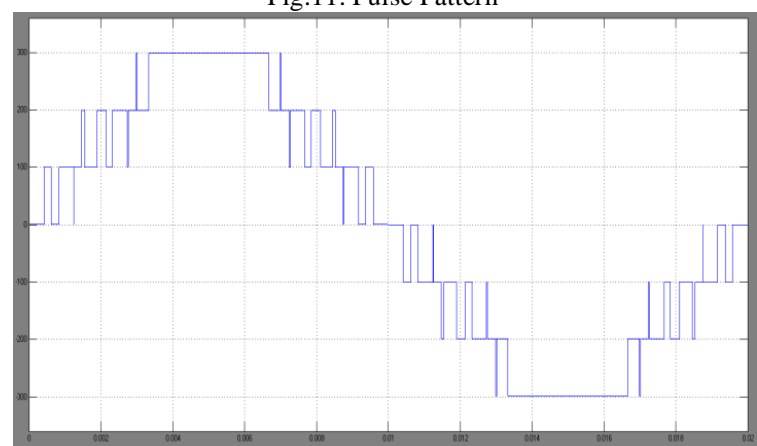

Fig.12. Output Voltage

The pulse pattern of $60^{\circ} \mathrm{PWM}$ technique signal is shown in fig. 11 and fig. 12 demonstrates the output voltage signal of $60^{\circ} \mathrm{PWM}$ technique signal.

Copyright to IJIREEICE

DOI 10.17148/IJIREEICE.2015.3305
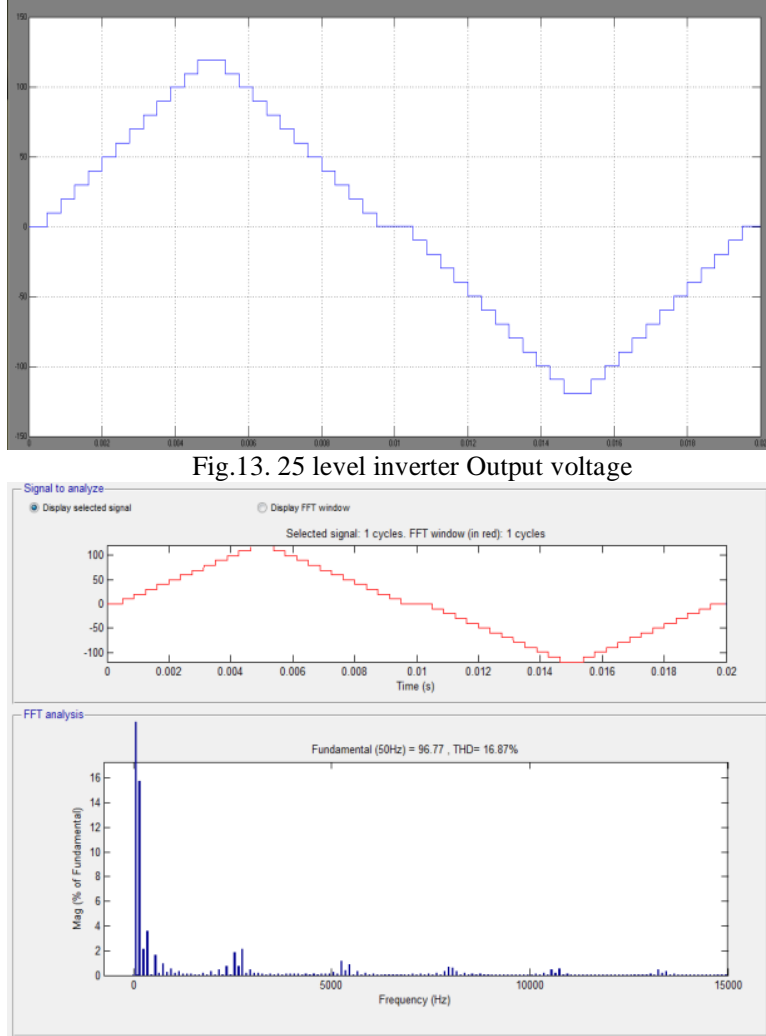

Fig.14. Voltage Spectrum

The fig.14 demonstrates the 25 level inverter output voltage signal and fig. 15 shows the voltage spectrum.

\section{Conclusion}

This project has proposed new multilevel inverter topology and new modulation technique. The whole reported has successfully projected the "multilevel inverter" as separate research topic. In this project work, the most actively developed and widely used multilevel topologies like cascaded multilevel inverter, diodeclamped multilevel inverter; multilevel dc-link inverters are studied. Based on the knowledge gained from literature survey, a modified multilevel inverter with $60^{\circ} \mathrm{PWM}$ switching strategy has been simulated. The proposed type utilizes only seven switches to synthesize seven levels.

\section{REFERENCES}

[1] S. M. Metev and V. P. Veiko, Laser Assisted Microtechnology, 2nd ed., R. M. Osgood, Jr., Ed. Berlin, Germany: Springer-Verlag, 1998. A.-Ch. Rufer, "An aid in the teaching of multilevel inverters for high power applications" 1995 IEEE.Power Electronics Specialists Conference, 1995. PESC '95 Record., 26th Annual IEEE. Publication Year: 1995 , Page(s): 347 - 352 vol.1

[2] S. Zhang, C. Zhu, J. K. O. Sin, and P. K. T. Mok, "A novel ultrathin elevated channel low-temperature poly-Si TFT," IEEE Electron Device Lett., vol. 20, pp. 569-571, Nov. 1999.

[3] M. Wegmuller, J. P. von der Weid, P. Oberson, and N. Gisin, "High resolution fiber distributed measurements with coherent OFDR," in Proc. ECOC'00, 2000, paper 11.3.4, p. 109.

[4] R. E. Sorace, V. S. Reinhardt, and S. A. Vaughn, "High-speed digital-to-RF converter,” U.S. Patent 5668 842, Sept. 16, 1997.

[5] (2002) The IEEE website. [Online]. Available: http://www.ieee.org/

[6] M. Shell. (2002) IEEE tran homepage on CTAN. [Online]. Available: http://www.ctan.org/tex-archive/macros/ latex /contrib. /supported/IEEEtran/

[7] FLEX Chip Signal Processor (MC68175/D), Motorola, 1996. 
[8] "PDCA12-70 data sheet," Opto Speed SA, Mezzovico, Switzerland.

[9] A. Karnik, "Performance of TCP congestion control with rate feedback: TCP/ABR and rate adaptive TCP/IP," M. Eng. thesis, Indian Institute of Science, Bangalore, India, Jan. 1999.

[10] J. Padhye, V. Firoiu, and D. Towsley, "A stochastic model of TCP Reno congestion avoidance and control," Univ. of Massachusetts, Amherst, MA, CMPSCI Tech. Rep. 9 9-02, 1999.

\section{BIOGRAPHIES}

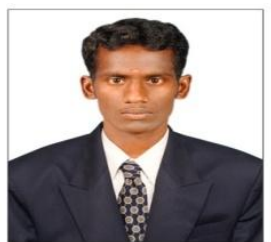

Mr. A.Mohandoss doing Master of Engineering in Electrical Drives and Embedded Control at R.V.S. College of Engineering and Technology, Coimbatore, Tamil Nadu. He received his Bachelor degree from VELTECH Engineering College, Avadi, Chennai. His area of interest in Electrical drives based industrial applicatio ns.

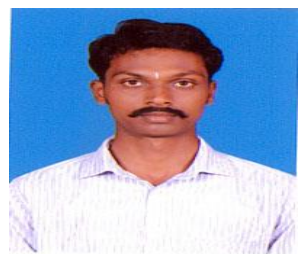

Mr.K.Sivaramachandran doing Master of Engineering in Embedded System Technologies at R.V.S. College of Engineering and Technology, Coimbatore, Tamil Nadu. He received his Bachelor degree from Karpagam University, Coimbatore. His area of interest in Embedded based real-time systems.

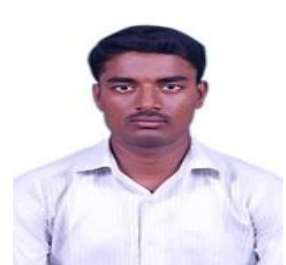

Mr.R.Radhakrishnan doing Master of Engineering in Power Electronics and Drives at Anna university Regional centre, Coimbatore, Tamil Nadu. He received his Bachelor degree from VELTECH Engineering College, Avadi, Chennai. His area of interest in real time based power electronics applications, power converters. 